\title{
Physiological responses of hens divergently selected on the number of chicks obtained from a single insemination
}

\author{
J. P. Brillard, C. Beaumont and M. F. Scheller \\ INRA, Station de Recherches Avicoles, 37380 Nouzilly, France
}

\begin{abstract}
A series of experiments was conducted in domestic fowl to investigate the consequences of five generations of divergent selection for increased $\left(\mathrm{L}^{+}\right)$or decreased $\left(\mathrm{L}^{-}\right)$numbers of hatched chicks. After artificial insemination with pooled ejaculates within the same line $\left(\mathrm{L}^{+}\right.$males $\times \mathrm{L}^{+}$hens or $\mathrm{L}^{-}$males $\times \mathrm{L}^{-}$hens), significant differences were observed between $\mathrm{L}^{+}$and $\mathrm{L}^{-}$hens for mean fertility rates $\left(\mathrm{L}^{+} 94.8 \%, \mathrm{~L}^{-} 70.2 \%\right.$, $P<0.0001)$ and for effective and maximum duration of fertility $(P<0.00001)$. A comparison of the overall laying performance and shell quality between the two selected lines showed that $\mathrm{L}^{-}$hens laid fewer eggs than $\mathrm{L}^{+}$hens $(P<0.00001)$ and $\mathrm{L}^{-}$eggs had poorer shell quality (shell breaking strength) than $\mathrm{L}^{+}$eggs $(P<0.00001)$. These observations were associated with significantly higher percentages of early embryo death in eggs from $\mathrm{L}^{-}$hens compared with $\mathrm{L}^{+}$hens. Another series of experiments revealed the presence of larger initial populations of spermatozoa in the sperm storage tubules as well as in the perivitelline layer of eggs from $\mathrm{L}^{+}$hens. The populations of spermatozoa in the sperm storage tubules of commercial laying hens inseminated with pooled semen samples from $\mathrm{L}^{+}$males was compared with those in hens inseminated with samples from $\mathrm{L}^{-}$males to determine whether the variations in oviductal sperm storage between the two lines were male dependent. No significant differences between the populations of spermatozoa present in the sperm storage tubules of either group of hens could be detected at any of the intervals examined after insemination (days 1,3 and 10). Finally, an experiment conducted on hens originating from the two selected lines indicated that the utero-vaginal junction of $\mathrm{L}^{+}$hens contained significantly more sperm storage tubules compared with $\mathrm{L}^{-}$hens $(P<0.01)$. It is concluded that selection based on overall reproductive performance modifies the number of eggs capable of developing viable embryos and also influences the efficacy of initial sperm storage by increasing or altering the population of sperm storage tubules located in the utero-vaginal junction. Such changes have major consequences on the duration of the fertile period, which in avian species is directly dependent on both the actual population of spermatozoa stored in the oviduct and on their rate of release from the storage sites.
\end{abstract}

\section{Introduction}

The mechanisms involved in the selection, storage and utilization of spermatozoa in the oviduct have not been fully elucidated in avian species. This is due to the difficulties in characterizing the exact role of the various physiological processes involved (for example, immunodependence of vaginal selection and sperm storage ability; for a review see Bakst $e$ t al., 1994) and the wide inter-individual variability in initial sperm acceptance (Brillard and Bakst, 1990; Brillard, 1992). However, use of several methodologies developed primarily to quantify the numbers of spermatozoa present in various parts of the oviduct may offer new insight into how the duration of the fertile period in selected lines is regulated

Received 3 December 1997. (in avian species the fertile period can be defined as the interval after sperm deposition during which a female lays fertile eggs). In avian species, the probability of fertilization of each egg is partly dependent on the density of spermatozoa present in the infundibulum, the site of fertilization. An estimate of sperm density can be obtained by evaluating the population of spermatozoa trapped in the perivitelline layer of oviposited eggs (Wishart, 1987) which is correlated with the actual population of spermatozoa stored in the sperm storage tubules (Brillard, 1993). Previous observations in domestic fowl have established that selection favouring a longer fertile period is feasible (Pingel and Planert, 1978; Beaumont, 1992). However, it has been demonstrated that such selection is accompanied by increased rates of embryonic death that ultimately severely impair the benefit of selection, that is, increasing the number 
of hatched chicks per hen (Pingel and Planert, 1978). An alternative model of selection based on the number of chicks hatched after artificial insemination has been proposed to overcome the negative consequences of the phenotypic and genetic correlations observed between the duration of the fertile period and embryo death (Beaumont, 1992; Beaumont et al., 1992). The number of chicks hatched depends on the number of eggs that are acceptable for incubation, the duration of the fertile period, and the probability of each embryo developing to hatching. The aim of the present study was to characterize the physiological consequences of five generations of divergent selection of fowl for increased or decreased numbers of hatched chicks.

\section{Materials and Methods}

\section{Husbandry and artificial insemination procedures}

The experimental selection of two divergent lines for increased $\left(\mathrm{L}^{+}\right)$or decreased $\left(\mathrm{L}^{-}\right)$numbers of hatched chicks was first conducted over five generations from a total of approximately 540 hens per line per generation. All hens from each generation were artificially inseminated twice intravaginally with $120 \times 10^{6}$ spermatozoa at 30 and 45 weeks of age. All eggs laid were recorded individually during the 3 weeks following each artificial insemination and were then incubated up to hatching. The subsequent generation was chosen from 90 hens and 18 males selected on their genetic value for the mean number of hatched chicks (estimated from the best linear unbiased predictor and an animal model). At the fifth generation, a total of 30 hens and 15 males were randomly chosen from the sub-population selected as parental stock ( 90 hens and 18 males per line). Sixty hens originating from a commercial slow-growing strain were used as controls. All birds were initially raised in floor pens up to 20 weeks of age, after which they were individually caged in environment-controlled chambers equipped with computer-assisted recorders of ovipositions to estimate laying rates. Birds were fed standard male or female diets ad libitum and provided with a $16 \mathrm{~h}$ light: $8 \mathrm{~h}$ dark photoperiod throughout the experiment (21-63 weeks of age). Hens were divided into four groups: group ${ }^{-}$ consisted of $\mathrm{L}^{-}$hens inseminated with semen from $\mathrm{L}^{-}$males; group ${ }^{++}$consisted of $\mathrm{L}^{+}$hens inseminated with semen from $\mathrm{L}^{+}$males; group $\mathrm{c}^{-}$(control) consisted of commercial slowgrowing hens inseminated with semen from $\mathrm{L}^{-}$males; and group $\mathrm{c}^{+}$(control) consisted of commercial slow-growing hens inseminated with semen from $\mathrm{L}^{+}$males. Pooled ejaculates collected from 7-8 males per group were used for each of the three experimental periods (period 1: 41-43 weeks; period 2: 51-53 weeks; period 3: 55-63 weeks of age, respectively). Intravaginal artificial insemination with either $240 \times 10^{6}$ spermatozoa per hen (periods 1 and 2) or $120 \times 10^{6}$ spermatozoa per hen (period 3) was carried out within $30 \mathrm{~min}$ of semen collection and at least $4 \mathrm{~h}$ after individual ovipositions (Brillard et al., 1987). The fertilization rates and percentages of embryo mortality were analysed during period 1 ; the quantification of spermatozoa in the perivitelline layer was determined during period 2; and sperm recovery from oviducts was performed during period 3.

\section{Shell breaking strength}

Laying rates and percentages of broken eggs were measured individually from 41 to 63 weeks of age, and tested using analysis of variance after transformation of percentages $(p)$ in arc $\sin \backslash p$ to test the effects of the selected line. In addition, the overall shell resistance of eggs originating from $\mathrm{L}^{-}$and $\mathrm{L}^{+}$hens was determined at 41 weeks using an Instron test machine on three consecutive eggs per hen. This test is also known as compression fracture force measurement and can be used as an indicator of tensile and shear fracture resistance of shell material (Voisey et al., 1979). The effects of selected line and hens within selected lines were tested using the SAS general linear model procedure (SAS, 1989).

\section{Fertility rates, duration of fertile period and embryo mortality (period 1)}

Eggs were collected each day from day 2 to 22 after artificial insemination and stored for a maximum of 7 days before incubation. The duration of the fertile period within each line was expressed using two definitions: effective duration $(D e)$, the period after artificial insemination during which a hen lays $100 \%$ fertile eggs; and maximum duration $(D m)$, the period up to oviposition of the last fertile egg (Romanoff and Romanoff, 1963). The percentages of fertile eggs were determined by candling eggs on day 7 of incubation. Eggs primarily classified as infertile were broken up for macroscopic examination of the blastodiscs. Three stages of embryo mortality were determined by candling on days 7 and 18 of incubation: early embryo mortality $<7$ days; medium embryo mortality 7-18 days; and late embryo mortality $>18$ days. The means of the two lines were compared using a $t$ test for $D e$ and $D m$ and an analysis of variance on the percentages $(p)$ after transformation in arc $\sin \vee_{p}$.

\section{Quantification of spermatozoa in the perivitelline layer (period 2)}

The populations of spermatozoa present in the perivitelline layer of eggs laid by group ${ }^{++}$or group ${ }^{--}$hens on days 3 and 10 after artificial insemination were revealed using the fluorescence method (Wishart, 1987; Brillard and Antoine, 1990) modified as follows: 4',6-diamidino-2phenilindole (DAPI) was replaced by Hoechst 33342 for brighter fluorescence and easier recognition of sperm heads (Brillard and Bakst, 1990). Sperm density in the perivitelline layer was estimated from 50 randomly chosen areas apart from the animal pole (ultraviolet fluorescence microscopy at $\times 400$ magnification). The population of spermatozoa in the perivitelline layer in each egg $(P)$ was estimated from individual yolks using the formula $P=N \times S$, in which 
$N=$ number of spermatozoa $\mathrm{mm}^{-2}$ membrane and $S=$ surface of egg membrane $\left(\mathrm{mm}^{2}\right)$. Assuming that avian yolks are approximately spherical, $S$ was estimated from $S=4 \pi R^{2}$, in which $R=$ yolk radius. The yolk radius $(R)$ was calculated from $V=4 / 3 \pi R^{3}$ in which $V=$ yolk volume = yolk weight $/ d$ ( $d=$ specific gravity of egg yolk, which is 1.036 in fowl; Romanoff and Romanoff, 1963). The number of spermatozoa in the perivitelline layer in eggs from group ${ }^{++}$and group ${ }^{--}$ hens was compared using the SAS general linear model (SAS, 1989) by fitting the effects of the four groups of hens after artificial insemination as well as the group $\times$ day interaction. As the day and group effects and their interaction were significant, the least square means were computed for each group and tested within each day by pairwise $t$ tests.

\section{Sperm recovery from oviducts (period 3)}

Spermatozoa were recovered from oviducts on days 1,3 and 10 in both the vagina and utero-vaginal junction using procedures described by Brillard and Bakst (1990) with minor modifications. Briefly, after hens were killed by intravenous injection of sodium pentobarbitol ( $2 \mathrm{ml}$ per hen) and the oviducts removed, the vaginal and utero-vaginal portions were identified using a binocular microscope adjusted to $\times 60$ magnification and were then clamped for isolation of each section. The vaginal portion was washed twice with $2 \mathrm{ml}$ Hank's balanced salts solution (HBSS; Sigma Chimie, L'ile d'Abeau-Chesnes), and the sperm storage tubule mucosa was removed from the underlying muscular layers by scraping with a scalpel. The scrapings were weighed and digested in a $2.5 \%(\mathrm{v} / \mathrm{v})$ solution of collagenase (Type XI from Sigma Chimie, L'Ile d'Abeau-Chesnes) diluted in HBSS. The digestions were performed using $500 \mu$ diluted collagenase for $400 \mathrm{mg}$ tissue, which was then rediluted 1:3 $(\mathrm{v} / \mathrm{v})$ in HBSS. Digestion was carried out in a waterbath at $37^{\circ} \mathrm{C}$ for $45 \mathrm{~min}$ with agitation. Preliminary observations revealed the absence of morphological damage from the treatment, thus allowing recovery of virtually the entire subpopulation of spermatozoa stored in the sperm storage tubules. Sperm density in both the washing fluids and digested tissues was estimated using haemocytometers (10 replicates per washing or digested sample, phase-contrast microscopy at $\times 400$ magnification). The populations of spermatozoa recovered from sperm storage tubules and vaginas were tested using the SAS general linear model procedure (SAS, 1989) and fitting the group and days after artificial insemination effects as well as their interaction. As both single effects and the interaction of group and days after artificial insemination were significant for the number of spermatozoa recovered from the sperm storage tubules, the least square means of the four groups were computed for each day.

\section{Quantitative estimates of sperm storage tubule populations}

A total of 28 hens $\left(14 \mathrm{~L}^{+}\right.$and $\left.14 \mathrm{~L}^{-}\right)$from the fifth generation of selection was randomly sampled and used in this study. After hens were killed and sperm storage tubule mucosa removed, the connective tissue was digested using collagenase as described previously. The exact time of enzymic digestion was determined using a binocular microscope $(\times 40$ magnification). Each digested preparation was then transferred to a $53 \mathrm{~mm}$ diameter Petri dish (cooled in melting ice) and adjusted with HBSS to a final volume of $2 \mathrm{ml}$. A square grid placed in the ocular surface $\left(9.36 \mathrm{~mm}^{2}\right)$ was used to quantify sperm storage tubules (20 fields randomly distributed in each dish). Sperm storage tubules were visibly distinct from basal uterine glands due to the large difference in diameter and shape of the tissues (mean diameter $20.6 \pm 0.5 \mathrm{~mm}$ and $35.4 \pm 1.5 \mathrm{~mm}$ for sperm storage tubules and basal uterine glands, respectively; values obtained from 30 uterine glands and 30 sperm storage tubules per hen, $n=10$ hens).

\section{Results}

\section{Laying performance and shell quality}

Overall laying rates over the experimental period were significantly greater in $\mathrm{L}^{+}$hens than in $\mathrm{L}^{-}$hens $(P<0.00001$; Table 1). In addition, the shell quality of eggs from $\mathrm{L}^{-}$hens was lower than that of $\mathrm{L}^{+}$hens, as revealed both by the percentage of broken eggs at oviposition $(11.1 \%$ versus $4.0 \%$; $P<0.00001)$ and also by the large differences in mean shell breaking pressures observed between the two lines $(P<0.00001$, Table 1$)$.

Table 1. Comparison of laying rates, shell quality, and efficient and maximum duration of fertility between two divergent lines of hens selected over five generations for increased and decreased number of hatched chicks

\begin{tabular}{lccc}
\hline Trait & $\mathrm{L}^{-}$ & $\mathrm{L}^{+}$ & Level of significance \\
\hline Laying rate (\%) & 75.0 & 83.0 & $P<0.05$ \\
Broken eggs (\%) & 11.1 & 4.0 & $P<0.00001$ \\
Shell breaking pressure (g) & $1159.0 \pm 95.0$ & $1601.0 \pm 88.0$ & $P<0.00001$ \\
Efficient duration of fertility (days) & $4.3 \pm 0.8$ & $12.0 \pm 0.8$ & $P<0.00001$ \\
Maximum duration of fertility (days) & $10.7 \pm 0.6$ & $15.1 \pm 0.5$ & $P<0.00001$ \\
\hline
\end{tabular}

$\mathrm{L}^{-}$, line selected for decreased numbers of hatched chicks; $\mathrm{L}$, line selected for increased numbers of hatched chicks. 


\section{Duration of fertile period, fertility rates and embryo mortality}

There were highly significant differences in the fertility (De and $D m$ ) of the two selected lines with fertile periods in $\mathrm{L}^{+}$hens exceeding those in $\mathrm{L}^{-}$hens by 7.7 and 4.4 days for $D e$ and $D m$, respectively $(P<0.00001$, Table 1$)$. Accordingly, the mean percentages of fertile eggs from the two lines showed that fertility rates of $\mathrm{L}^{+}$eggs were consistently greater than those of $\mathrm{L}^{-}$eggs, the mean differences in fertility being 24.6 and $53.0 \%$ during weeks 1 and 2 after artificial insemination, respectively $(P<0.0001$, Table 2$)$. The percentage of fertility

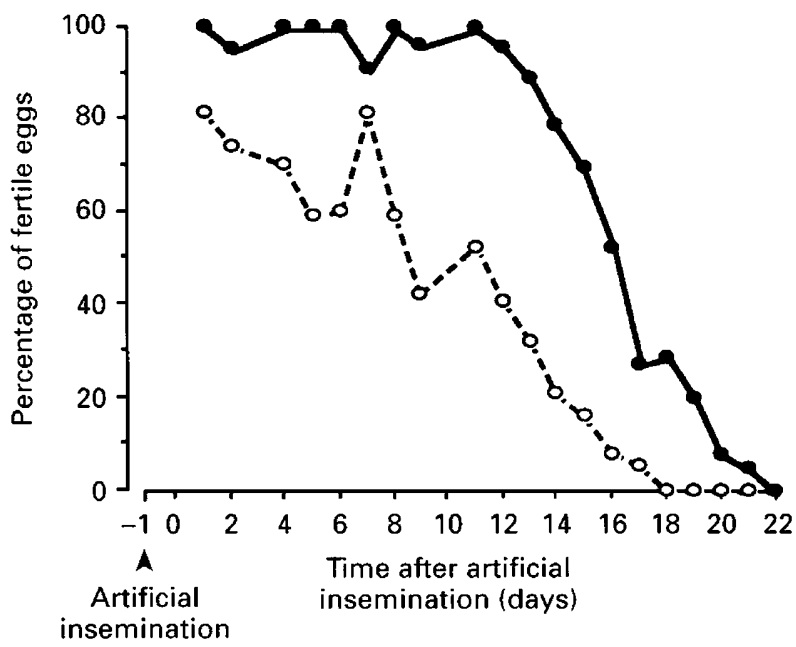

Fig. 1. Fertility of eggs originating from two lines of hens selected for $\left(\boldsymbol{O}\right.$, group $\left.^{++}\right)$and against $\left(0\right.$, group $\left.{ }^{-}\right)$the ability to produce hatched chicks after artificial insemination $\left(240 \times 10^{6}\right.$ spermatozoa per hen) at 41 weeks of age; $n=30$ hens per group. Mean fertility (\%) \pm confidence $(5 \%)$ interval in group ${ }^{++}$and group - : $94.8 \pm 3.7 \%$ and $70.2 \pm 7.7 \%$ (week 1 ), $89.4 \pm 5.2 \%$ and $36.4 \pm 8.1 \%$ (week 2 ), $17.6 \pm$ $6.4 \%$ and $5.2 \pm 3.7 \%$ (week 3 ), respectively. of eggs from $\mathrm{L}^{+}$hens was always greater than in $\mathrm{L}^{-}$hens over days 2-22 after artificial insemination (Fig. 1).

During the 2 weeks after insemination, the percentage of early embryo mortality in fertile eggs was greater in eggs from $\mathrm{L}^{-}$hens $(P<0.01$, Table 2$)$. In contrast, similar percentages of embryo survival were observed in the two lines during the later stages of embryo development (Table 2). The percentage of hatched eggs was constantly greater in $\mathrm{L}^{+}$hens irrespective of the week after insemination.

\section{Populations of spermatozoa in the perivitelline membrane}

The perivitelline layer of eggs from group ${ }^{++}$contained significantly larger populations of spermatozoa $(P<0.01)$ despite wide individual variations within lines (coefficient of variation $>40 \%$, Table 3 ). The numbers of perivitelline

Table 3. Populations of spermatozoa in the perivitelline layer of eggs laid on days 3 and 10 after intravaginal insemination in two divergent lines of hens selected over five generations for increased and decreased numbers of hatched chicks

\begin{tabular}{lll}
\hline & \multicolumn{2}{c}{ Number of spermatozoa $\left(\times 10^{3}\right)$} \\
\cline { 2 - 3 } & 3 days after insemination & 10 days after insemination \\
\hline Group $^{--}$ & $23722 \pm 10097^{\mathrm{a}}(n=22)$ & $2122 \pm 511^{\mathrm{c}}(n=19)$ \\
Group $^{++}$ & $59643 \pm 8480^{\mathrm{b}}(n=27)$ & $8691 \pm 1526^{\mathrm{d}}(n=23)$
\end{tabular}

Group ; hens from line selected for decreased numbers of hatched chicks (L ) inseminated with semen from $\mathrm{L}^{-}$males; group ${ }^{++}$, hens from line selected for increased numbers of hatched chicks $\left(\mathrm{L}^{+}\right)$inseminated with semen from $\mathrm{L}^{+}$males.

Hens were inseminated with $240 \times 10^{6}$ spermatozoa.

Means within the same column ( \pm SEM) with different superscripts are significantly different $(P<0.01)$.

Table 2. Comparison of fertility, embryo mortality and hatchability of eggs originating from two divergent lines of hens selected over five generations for increased and decreased numbers of hatched chicks

\begin{tabular}{|c|c|c|c|c|c|c|}
\hline \multirow[t]{2}{*}{ Fertility trait } & \multicolumn{3}{|c|}{$\begin{array}{c}\text { Week } 1 \text { ( } 2-8 \text { days after artificial } \\
\text { insemination) }\end{array}$} & \multicolumn{3}{|c|}{$\begin{array}{c}\text { Week } 2 \text { (9-15 days after artificial } \\
\text { insemination) }\end{array}$} \\
\hline & $\mathrm{L}^{-}$ & $\mathrm{L}^{+}$ & $\begin{array}{c}\text { Level of } \\
\text { significance }\end{array}$ & $\mathrm{L}^{-}$ & $\mathrm{L}^{+}$ & $\begin{array}{l}\text { Level of } \\
\text { significance }\end{array}$ \\
\hline $\mathrm{F} / \mathrm{I}(\%)$ & 70.2 & 94.8 & $P<0.0001$ & 36.4 & 89.4 & $P<0.0001$ \\
\hline $\mathrm{EEM} / \mathrm{F}(\%)$ & 23.3 & 3.3 & $P<0.01$ & 23.3 & 3.3 & $P<0.01$ \\
\hline MEM/F-EEM $(\%)$ & 0.6 & 1.9 & $P>0.05$ & 2.4 & 2.2 & NS \\
\hline LEM/F-EEM-MEM (\%) & 5.7 & 5.3 & $P>0.05$ & 11.3 & 8.9 & NS \\
\hline $\mathrm{H} / \mathrm{I}(\%)$ & 49.1 & 84.6 & $P<0.01$ & 17.9 & 73.5 & $P<0.001$ \\
\hline $\mathrm{H} / \mathrm{F}(\%)$ & 69.9 & 89.2 & $P<0.01$ & 49.1 & 82.2 & $P<0.01$ \\
\hline
\end{tabular}

$\mathrm{L}^{-}$, line selected for decreased numbers of hatched chicks; $\mathrm{L}^{+}$, line selected for increased numbers of hatched chicks.

Number of eggs incubated per week: week $1,144\left(\mathrm{~L}^{-}\right)$and $134\left(\mathrm{~L}^{+}\right)$; week $2,135\left(\mathrm{~L}^{-}\right)$and $130\left(\mathrm{~L}^{+}\right)$.

$\mathrm{F}$, number of fertile eggs; I, number of incubated eggs; $\mathrm{H}$, number of hatched chicks; EEM, early embryo mortality (<7 days incubation); MEM, medium embryo mortality (7-18 days incubation); LEM, late embryo mortality (> 18 days incubation).

NS, not significant. 
(a)

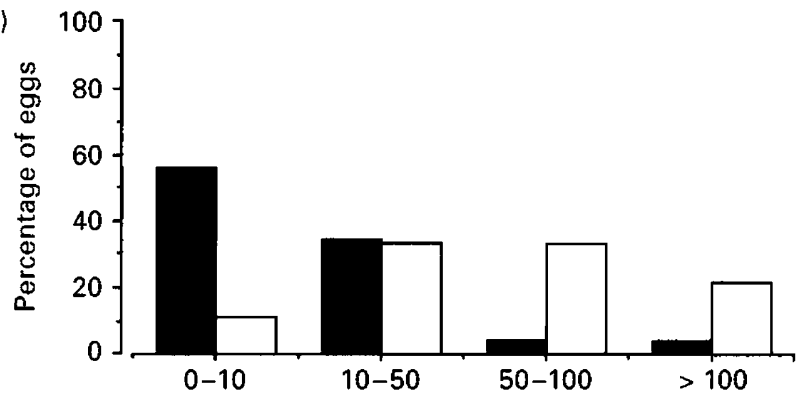

Number of spermatozoa

in the perivitelline layer per egg $\left(\times 10^{3}\right)$

(b)

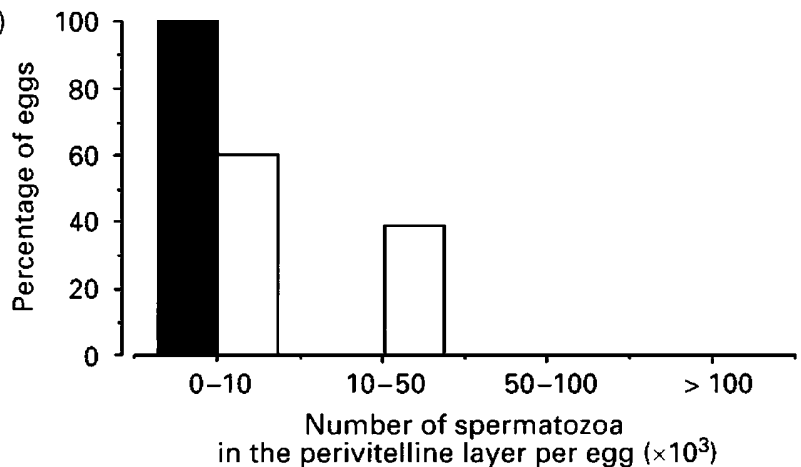

Fig. 2. Distribution of the populations of spermatozoa in the perivitelline layer in eggs laid on (a) day 3 and (b) day 10 after artificial insemination of hens selected for $\left(\square\right.$, group $\left.{ }^{++}\right)$and against $\left(\boldsymbol{\omega}\right.$, group $\left.^{-}\right)$the ability to produce hatched chicks ( $n=30$ hens per group). Hens were inseminated with $240 \times 10^{6}$ spermatozoa. spermatozoa varied between 23722 and 59643 on day 3 and between 2122 and 8691 on day 10 after insemination in groups $^{--}$and ${ }^{++}$, respectively. There were also differences in the intraclass distribution of the populations of perivitelline spermatozoa between lines (Fig. 2), with very few (day 3) or no eggs (day 10) from group ${ }^{--}$containing more than 50000 spermatozoa. In contrast, similar or greater numbers of spermatozoa were recovered in approximately 50\% (day 3 ) and $40 \%$ (day 10 ) of the eggs from group ${ }^{++}$hens.

\section{Sperm storage efficiency in the utero-vaginal junction}

The populations of spermatozoa recovered from the utero-vaginal junction of both control and experimental ( $\mathrm{L}^{-}$ or $\mathrm{L}^{+}$) hens on days 1,3 and 10 after insemination showed that there was no significant group effect $(P>0.05)$ in the vagina, while the interval after artificial insemination effect was significant $(P<0.05$; Table 4$)$. Both the group and the interval after artificial insemination effects were significant $(P<0.05$ and $P<0.01$, respectively). There were approximately two and eleven times more spermatozoa recovered in the sperm storage tubules from $\mathrm{L}^{+}\left(\right.$group $\left.^{++}\right)$ than from $\mathrm{L}^{-}$(group ${ }^{--}$) hens on days 1 and 10 , respectively. In contrast, the two control groups of hens inseminated with pooled semen samples from both $\mathrm{L}^{-}$(group ${ }^{-}$) and $\mathrm{L}^{+}$ (group $\left.^{++}\right)$males showed no significant difference $(P>0.05)$ for this trait at any of the intervals examined. The initial populations of spermatozoa (day 1 ) recovered from both control groups $\left(769 \times 10^{3}\right.$ and $844 \times 10^{3}$ in groups $\mathrm{c}^{-}$and $\mathrm{c}^{+}$,

Table 4. Numbers of spermatozoa recovered from vagina and sperm storage tubules after artificial insemination of two divergent lines of hens selected over five generations for increased and decreased numbers of hatched chicks

\begin{tabular}{|c|c|c|c|c|}
\hline & \multirow[b]{2}{*}{ Group } & \multicolumn{3}{|c|}{ Number of spermatozoa $\left(\times 10^{3}\right)$} \\
\hline & & $\begin{array}{l}1 \text { day after } \\
\text { insemination }\end{array}$ & $\begin{array}{l}3 \text { days after } \\
\text { insemination }\end{array}$ & $\begin{array}{l}10 \text { days after } \\
\text { insemination }\end{array}$ \\
\hline \multirow[t]{4}{*}{ Vagina } & -- & $37 \pm 13$ & $27 \pm 14$ & 0 \\
\hline & ++ & $65 \pm 35$ & $30 \pm 14$ & $10 \pm 8$ \\
\hline & $c^{-}$ & $150 \pm 50$ & $30 \pm 13$ & $1 \pm 1$ \\
\hline & $\mathrm{c}^{+}$ & $99 \pm 44$ & $56 \pm 36$ & $8 \pm 5$ \\
\hline \multirow[t]{4}{*}{ Sperm storage tubules } & -- & $543 \pm 97^{a}$ & $246 \pm 50^{\mathrm{a}}$ & $14 \pm 10^{\mathrm{a}}$ \\
\hline & ++ & $1044 \pm 170^{\mathrm{b}}$ & $300 \pm 83^{a}$ & $157 \pm 43^{b}$ \\
\hline & $c^{-}$ & $769 \pm 78^{\mathrm{ab}}$ & $240 \pm 55^{\mathrm{a}}$ & $58 \pm 15^{a}$ \\
\hline & $\mathrm{c}^{+}$ & $844 \pm 162^{a b}$ & $299 \pm 70^{a}$ & $60 \pm 25^{\mathrm{a}}$ \\
\hline \multirow[t]{4}{*}{ Number of hens } & -- & 9 & 9 & 9 \\
\hline & ++ & 9 & 8 & 8 \\
\hline & $c^{-}$ & 9 & 8 & 8 \\
\hline & $\mathrm{c}^{+}$ & 9 & 8 & 8 \\
\hline
\end{tabular}

Group , hens from line selected for decreased numbers of hatched chicks $\left(\mathrm{L}^{-}\right)$inseminated with semen from $\mathrm{L}^{-}$males; group ${ }^{++}$, hens from line selected for increased numbers of hatched chicks $\left(\mathrm{L}^{+}\right)$inseminated with semen from $\mathrm{L}^{+}$males; group $\mathrm{c}^{-}$(control), commercial slow-growing hens inseminated with semen from $\mathrm{L}^{-}$males; group $\mathrm{c}^{+}$(control), commercial slow-growing hens inseminated with semen from $\mathrm{L}^{+}$males.

Hens were inseminated with $120 \times 10^{h}$ spermatozoa.

Means $( \pm$ SEM) with different superscripts within the same column are significantly different $(P<0.05)$. 
respectively) were intermediate to those found in group ${ }^{--}$(L $\left.543 \times 10^{3}\right)$ and group ${ }^{++}\left(\mathrm{L}^{+} 1044 \times 10^{3}\right)$ hens. Finally, the percentages of spermatozoa recovered on day 1 after artificial insemination (that is, on the day with the highest numbers of spermatozoa in the sperm storage tubule) ranged from $0.5 \%$ (group ${ }^{-}$) to $0.9 \%\left(\right.$ group $^{++}$) of the initial inseminated dose.

\section{Comparison of the sperm storage tubule populations}

The mean populations of sperm storage tubules present in the utero-vaginal junction were $2241 \pm 121$ and $2957 \pm 140$ in $\mathrm{L}^{-}$and $\mathrm{L}^{+}$hens, respectively. These differences were highly significant $(P<0.001)$.

\section{Discussion}

The present study shows that selection for or against the number of chicks obtained from a single insemination has a major effect on each of the components of this composite trait. Previous observations in various poultry species have shown that a number of reproductive traits are heritable: laying rates (for a review see Fairfull and Gowe, 1990), shell deformation (Potts and Washburn, 1985), duration of fertile period (Pingel and Planert, 1978), and embryo survival and fertility (Crittenden et al. 1957; Custodio and Dacosta, 1988). The results also confirmed that the number of eggs capable of producing a viable embryo can be modified by selection on the number of hatched chicks, which is itself dependent on the actual number of oviposited eggs, their capacity for fertilization and their ability to develop a normal embryo. Moreover, traits other than those directly related to laying rate or shell quality were shown to exert an influence on the overall reproductive performance of hens. Thus, divergent selection on the number of hatched chicks was accompanied by wide inter-line variations favouring the $\mathrm{L}^{+}$versus the $\mathrm{L}^{-}$line for each of the fertility dependent traits examined ( $D e$, $D m$ and percentage of fertile eggs at weeks 1 and 2 after artificial insemination).

These observations and the absence of significant differences between the two control groups suggest that the variations observed were mainly attributable to the hens rather than the males. The significant differences in the populations of sperm storage tubules in the two selected lines support the hypothesis that the changes in fertility parameters are a result of major changes originating from selection that ultimately influence the efficacy of initial sperm storage by modifying the population of sperm storage tubules.

These results contradict the observations of Van Krey et al. (1971) who proposed that fertility differences between two lines of hens were due to factors other than differences in numbers of sperm storage tubules. Our conclusions are supported by the large differences observed between the numbers of sperm storage tubules present in the two divergently selected lines (about 25\% fewer sperm storage tubules in $\mathrm{L}^{-}$compared to $\mathrm{L}^{+}$hens) and by the approximately 2:1 ratio in the populations of spermatozoa recovered from the sperm storage tubules on day 1 after insemination, which is the time of maximum sperm storage in domestic hens (Brillard, 1993). Brillard (1993) reported the recovery of approximately $0.9 \%$ of inseminated spermatozoa from the sperm storage tubule, which is similar to the percentage recovery $(0.8 \%)$ observed in turkeys (Brillard and Bakst, 1990 ). In the present study, the percentages of spermatozoa stored in the sperm storage tubules ranged from approximately $0.5 \%$ ( $\mathrm{L}^{+}$hens) to $0.9 \%$ ( $\mathrm{L}^{-}$hens) of the initial amount inseminated. These percentages are greater than those reported by McDaniel et al. (1997) who used a different experimental approach to quantify the spermatozoa stored in the sperm storage tubules (incubation of spermatozoa with bisbenzimide before artificial insemination). The discrepancy in the results may be due to differences in either the overall quality of spermatozoa or in the initial sperm storage acceptance of the hens used. In addition, the procedures used by McDaniel et al. (1997) may have altered the fraction of the sperm population deposited intravaginally, therefore increasing the intensity of selection of spermatozoa in the vagina. In the present study, Type XI collagenase was used to free the spermatozoa from the sperm storage tubules, which allows the recovery of virtually the entire sperm population without the need to grind the tubule tissue as was performed by Brillard and Bakst (1990) in their study of turkeys. There was a significant difference in the incidence of early embryo mortality between the two lines, with over four times more embryo deaths in eggs from $\mathrm{L}^{-}$compared with $\mathrm{L}^{+}$hens. Previous studies in fowl (McDaniel et al., 1979) have shown that early embryo mortality increases in eggs with low specific gravity, that is, in eggs with low shell quality. Bilgili and Renden (1987) reported that higher percentages of empty sperm storage tubules were observed in hens primarily classified as laying a majority of eggs without shells. These observations suggest causal dependence between overall shell quality (indirectly quantifiable by determining either the specific gravity of eggs or, more accurately, shell breaking strength) and early embryo mortality. This may be explained by the high degree of water loss occurring in eggs with low shell quality (McDaniel et al., 1979) and oviposition of blastoderm from eggs with thin shells before they have the capacity to survive. A direct link between the ability of a hen to store spermatozoa and to produce eggs with high or low shell quality remains questionable as the two sites responsible for these functions in the oviduct (the vagina for sperm selection and the uterus for shell deposition) are anatomically distinct. However, it is possible that selecting two lines on the number of hatched chicks results in the modification of a series of oviduct-dependent traits, including those involved in the control of shell quality, fertility and early embryo survival, even if no direct correlation between these traits has been observed (Fairfull and Gowe, 1990).

The present study supports the hypothesis that changes in sperm storage capacity in the oviduct are at least partly responsible for the differences in fertility observed between the two selected lines. However, the possibility that changes also occur in initial sperm selection in the oviduct cannot be entirely discarded. Previous work in fowl by Steele and Wishart (1992) demonstrated that the vagina rather than the sperm storage tubule is capable of selecting spermatozoa 
before they are stored in the utero-vaginal junction. These experiments also revealed the presence of immunoglobulins (IgA or IgG), mainly on the tail region of spermatozoa, in more than $85 \%$ of the sperm population recovered from vaginas, while less than $7 \%$ of spermatozoa stored in the sperm storage tubules had bound immunoglobulins. It remains to be established whether the divergent selection conducted in the present study also modified these mechanisms.

In conclusion, divergent selection of domestic hens on the number of hatched chicks influences the capacity for initial sperm storage by modifying the population of sperm storage tubules located in the utero-vaginal junction and also influences the number of eggs capable of developing viable embryos. These results demonstrate that the selected trait plays a major role in improving or disrupting the main oviductal functions in domestic hens.

The authors are grateful to G. J.Wishart for his corrections and valuable comments regarding this manuscript.

\section{References}

Bakst MR, Wishart GJ and Brillard JP (1994) Oviducal sperm selection, transport and storage in poultry Poultry Science Reviews $5117-143$

Beaumont C (1992) Genetic parameters of the duration of fertility in hens Canadian Journal of Animal Science 72 193-201

Beaumont C, Brillard JP, Millet N and de Reviers M (1992) Comparison of various characteristics of duration of fertility in hens British Poultry Science 33 649-661

Bilgili SF, Renden JA and Krista LM (1987) Relationships among fertility, sperm storage and shell quality Poultry Science 28 307-318

Brillard JP (1992) Factors affecting oviductal sperm storage in domestic fowl following artificial insemination Animal Reproduction Science 27 247-256

Brillard JP (1993) Sperm storage and transport following natural mating and artificial insemination Poultry Science 72 923-928

Brillard JP and Antoine H (1990) Storage of sperm in the utero-vaginal junction and its incidence on the numbers of spermatozoa present in the perivitelline layer of hen's eggs British Poultry Science 31 701-710

Brillard JP and Bakst MR (1990) Quantification of spermatozoa in the sperm storage tubules of turkey hens and the relation to sperm numbers in the perivitelline layer of eggs Biology of Reproduction 43 271-275

Brillard JP, Galut O and Nys Y (1987) Possible causes of subfertility in hens following inseminations near the time of oviposition British Poultry Science 28307-318

Crittenden LB, Bohren BB and Anderson VL (1957) Genetic variance and covariance of the components of hatchability in New Hampshires Poultry Science 36 90-103

Custodio RWS and Dacosta MN (1988) Genetics of reproductive traits obtained from hierarchical matings in meat-type chickens Proceedings 18th World Poultry Contress, Nagoya 472-473

Fairfull RW and Gowe RS (1990) Genetics of egg production in chickens. In Poultry Breeding and Genetics pp 705-759 Ed RD Crawford. Elsevier Scientific Publications, Amsterdam

McDaniel GR, Roland DR and Coleman MA (1979) The effect of egg shell quality on hatchability and embryonic mortality Poultry Science 58 10-13

McDaniel CD, Bramwell RK and Howarth B (1997) Development of a novel fluorescence technique for quantifying the total number of spermatozoa stored in the utero-vaginal junction of hens Journal of Reproduction and Fertility 109 173-179

Pingel H and Planert C (1978) Untersuchung über die möglichkeiten der verlängerung der befruchtungspersistenz Proceedings 16th World Poultry Congress, Rio de Janeiro $2116-125$

Potts PL and Washburn KW (1985) Genetic variation in shell strength and its relationship to egg size Poultry Science 64 1249-1256

Romanoff AL and Romanoff AJ (1963) Structure. In The Avian Egg pp 113-175. $\mathrm{J}$ Wiley and Sons, New York

SAS (1989) Procedures Guide for Personal Computers SAS Institute Inc.

Steele $M$ and Wishart GJ (1992) Characterisation of a mechanism impeding sperm transport through the vagina of the chicken Proceedings 12th International Congress of Animal Reproduction 1593-1595

Van Krey HP, Siegel PB and Leighton, Jr T (1971) Repeatability estimates and quantification of utero-vaginal sperm-host gland numbers and population patterns Biology of Reproduction 431-34

Voisey PW, Hamilton RMG and Thomson BK (1979) Laboratory measurements of egg shell strength. 2. The quasi-static compression, puncture, non-destructive deformation, and specific gravity methods applied to the same egg Poultry Science 58 288-294

Wishart GJ (1987) Regulation of the fertile period in the domestic fowl by numbers of oviducal spermatozoa, as reflected by those trapped in laid eggs Journal of Reproduction and Fertility 80 493-498 